\title{
Interferência alelopática de folhas de cártamo sobre espécies oleaginosas
}

\author{
Thaliny Bonamigo ${ }^{1 *}$ \\ Andréa Maria Teixeira Fortes ${ }^{2}$ \\ Tassiane Terezinha Pinto ${ }^{3}$ \\ Fernanda Melo Gomes ${ }^{4}$ \\ Jéssica da Silva ${ }^{5}$ \\ Camila Vanessa Buturi ${ }^{2}$ \\ ${ }^{1}$ Faculdade de Ciências Agrárias, Universidade Federal da Grande Dourados \\ Rodovia Dourados - Itahum, km 12, CEP 79.804-970, Dourados - MS, Brasil \\ ${ }^{2}$ Laboratório de Fisiologia Vegetal, Universidade Estadual do Oeste do Paraná, Cascavel - PR, Brasil \\ ${ }^{3}$ PPG em Biologia Vegetal, Universidade Federal de Santa Catarina, Florianópolis - SC, Brasil \\ ${ }^{4}$ Laboratório de Sementes, Universidade Federal do Ceará, Fortaleza - CE, Brasil \\ ${ }^{5}$ Biologia Aplicada à Agropecuária, Universidade Estadual Paulista, Jaboticabal - SP, Brasil \\ * Autor para correspondência \\ thalibonamigo@hotmail.com
}

Submetido em 04/05/2012

Aceito para publicação em 11/03/2013

\section{Resumo}

O objetivo do trabalho foi avaliar, em condições laboratoriais, a interferência alelopática do extrato aquoso de folhas de cártamo (Carthamus tinctorius L.) na germinação e crescimento inicial de plântulas de girassol e canola. Estes testes preliminares indicarão a necessidade de maiores estudos, para inserção das espécies em sistemas de plantio direto. Os ensaios foram realizados sobre sementes condicionadas em placas de Petri umedecidos com concentrações de extrato aquoso de cártamo a 20, 40, 60, 80 e 100\%, além da testemunha somente com água destilada. As placas foram armazenadas em câmara de germinação, do tipo BOD, com temperatura e fotoperíodo controlados. O delineamento experimental foi inteiramente casualizado e os parâmetros avaliados foram: percentagem de germinação, tempo e velocidade média de germinação, assim como comprimento médio de raiz. Os parâmetros foram submetidos ao Teste F, sendo as médias comparadas pelo teste de Tukey a 5\% de probabilidade. Foi verificado efeito alelopático do extrato aquoso de cártamo sobre canola, sendo este prejudicial à emergência e crescimento inicial das plântulas.

Palavras chave: Alelopatia; Canola; Carthamus tinctorius (L.); Girassol; Plantio direto

\section{Abstract}

Allelopathic interference of safflower leaves with oilseed species. The objective of this study was to evaluate, under laboratory conditions, the allelopathic interference of an aqueous extract of safflower (Carthamus tinctorius L.) leaves with seed germination and early growth of seedlings of sunflower and canola. These preliminary tests indicate the need for further studies for inclusion of this species in no-till systems. 
The tests were conducted on seeds conditioned in Petri dishes moistened with five different concentrations of safflower aqueous extract and distilled water for the control. The plates were stored in a germination chamber with controlled temperature and photoperiod. The experimental design was completely randomized, and the parameters evaluated were percentage, time and average speed of germination, as well as average length of roots. The parameters were subjected to $\mathrm{F}$ tests, where the averages were compared by Tukey's test at $5 \%$ probability. The results demonstrated an allelopathic effect of safflower aqueous extract on canola, detrimental to seedling emergence and early growth.

Key words: Allelopathy; Canola; Carthamus tinctorius (L.); Sunflower; Tillage

\section{Introdução}

A alelopatia ocorre na natureza e é um mecanismo pelo qual algumas plantas, algas, bactérias ou fungos podem interferir em organismos próximos, afetando de forma benéfica ou maléfica o crescimento e/ou o desenvolvimento das espécies, e ainda, o sistema biológico. Tais interações ocorrem devido à liberação de substâncias químicas (aleloquímicos) provenientes do metabolismo secundário (IAS, 2012).

Os aleloquímicos são produzidos em diferentes partes da planta e são liberados por processos como lixiviação, exsudação radicular e volatilização, sendo responsáveis por múltiplas interações entre os diferentes organismos (BORELLA; PASTORINI, 2009). Essas interações possuem importante função ecológica e contribuem para a evolução e co-evolução das espécies animais e vegetais, pois interferem na conservação, germinação, dormência, crescimento das plantas, dentre outras características, e assim, podem influenciar a competição entre espécies (LACHER, 2000; OLIVEIRA et al., 2002).

Atualmente, estudos relacionados ao potencial alelopático das plantas são objeto de muitas pesquisas, podendo ser mencionados: Silva et al. (2011), Carvalho et al. (2012), Lousada et al. (2012) e Oliveira et al. (2012), pois são métodos naturais, que podem ser utilizados como estratégias de manejo de plantas infestantes, visando reduzir o uso de muitos produtos químicos, e ainda, espécies potencialmente alelopáticas que beneficiem outras plantas, podem ser utilizadas para aperfeiçoar os métodos de agricultura sustentável, como o plantio direto, rotação e consorciamento de culturas.

Estas práticas de agricultura sustentável proporcionam a interação entre as plantas cultivadas.
Isto permite o aumento da diversidade, ocasionando melhor distribuição temporal de renda, visto que, haverá produção de diferentes culturas em várias épocas do ano (MACÍAS et al., 2007). Neste contexto, a alelopatia quando utilizada juntamente com métodos de plantio direto, rotação e consórcio de culturas, pode aumentar a produtividade das espécies de forma que os próprios vegetais forneçam os componentes necessários para a cultura, além dos benefícios ao meio ambiente (CARVALHO, 2006).

No entanto, é necessário o conhecimento das espécies introduzidas e seus efeitos sobre as demais. A família botânica Asteraceae engloba tanto espécies com importância econômica, como a losna (Artemisia absinthium L.) e a camomila (Matricaria recutita L.), quanto espécies prejudiciais em agrossistemas como o picão-preto (Bidens pilosa L.), que também possui finalidade medicinal (LORENZI; MATOS, 2008). Dentre as espécies desta família, existem várias plantas de uso medicinal e utilizadas na agricultura que possuem compostos alelopáticos já identificados (BORGO et al., 2010; GASPARRETTO et al., 2010).

$\mathrm{Na}$ cultura do girassol são encontrados terpenos e compostos fenólicos (KUPIDLOWSKA et al., 2006). Estas substâncias limitam o crescimento de plantas no solo (TAIZ; ZEIGER, 2009). Outra espécie que também possui aleloquímicos é o crisântemo (Chrysanthemum cinerariaefolium L.). Os piretróides encontrados nessa planta possuem funções importantes na defesa dos vegetais, pois apresentam grande atividade inseticida, sendo economicamente, o grupo mais importante de inseticidas naturais (BRASIL, 2005).

Os metabólitos secundários dessa família, por possuírem interesse médico e farmacológico, são objetos de estudo de muitas pesquisas (VERDI et al., 2005). 
Também da mesma família, o Carthamus tinctorius L., popularmente conhecido como cártamo ou açafrãobastardo, é uma cultura apreciada desde a antiguidade por ser fonte de corantes, para o tingimento de tecidos. Esta espécie é utilizada em muitos países como cultura oleaginosa, mas existem cultivares com características associadas à produção de flores, ainda pouco conhecidas no Brasil (OLIVEIRA, 2007; PINTÃO; SILVA, 2008).

A cultura de cártamo é de interesse econômico por oferecer alta variabilidade de matérias primas (VIVAS, 2002). O cártamo é uma espécie anual, com ciclo de aproximadamente 140 dias, rústica, que por ser originária dos desertos mexicanos, oferece alta resistência à falta de água e baixa umidade relativa do ar, mostrando-se insensível às adversidades climáticas, especialmente a estiagens e diferentes tipos de solo, podendo ser cultivada no verão e no inverno. Além disso, a presença de espinhos em toda sua estrutura afasta os pássaros que, efetivamente, causam prejuízos, em outras culturas, alimentando-se de sementes. Essas características permitem que esta espécie seja utilizada em sistemas de consórcio, rotação ou plantio direto com espécies de verão ou inverno, dependendo da região (INTA, 2008; RURAL, 2013).

Além disso, atualmente, o cártamo tem sido alvo de estudos devido ao seu grande potencial para produção de biocombustíveis. A cultura já é amplamente cultivada com essa finalidade em muitos países, no entanto, pesquisas estão sendo realizadas, com o propósito de aumentar a produção e consequentemente o rendimento do seu óleo (ULLAH; BANO, 2011; EL-LATTIEF, 2012).

Assim, devido a sua grande importância, esta espécie vem sendo sugerida por muitos autores para a introdução em sistemas de agricultura sustentável. Porém, estudos comprovaram a presença de compostos aleloquímicos, conhecidos como ácidos fenólicos (ABUD et al., 2010). Segundo Ferreira e Áquila (2000), todas as plantas produzem metabólitos secundários característicos, e estes podem exercer diferentes efeitos sobre as espécies vegetais, sendo assim, é necessário o estudo das diferentes espécies para introdução dessas em um mesmo agroecossistema.
No entanto, apesar de existirem estudos que comprovem que o cártamo possui substâncias aleloquímicas, trabalhos que relatam o potencial alelopático desta espécie sobre espécies agrícolas são escassos. Portanto, é necessário o estudo dos efeitos que o cártamo pode exercer sobre outras plantas.

Em função disto, o objetivo deste trabalho foi verificar, em condições laboratoriais, a existência de interferência alelopática do cártamo sobre a germinação e crescimento inicial de plântulas de canola (Brassica napus L.) (Brassicaceae) e girassol (Asteraceae), visando acompanhar a possibilidade de inserção destas espécies em sistemas de plantio direto.

\section{Material e Métodos}

Os experimentos foram conduzidos no ano de 2010, no Laboratório de Fisiologia Vegetal da Universidade Estadual do Oeste do Paraná, campus de Cascavel.

O material utilizado consistiu em placas de Petri com papel filtro para sementes pequenas, e rolos de papel tipo Germitest, cada qual com três camadas para sementes maiores, o qual foi esterilizado em autoclave a $121^{\circ} \mathrm{C}$ por $20 \mathrm{~min}$, conforme Bortolini e Fortes (2005).

As placas de Petri contendo 25 sementes de canola, foram umedecidas com $6 \mathrm{~mL}$ da solução, já para os rolos de papel que continham 50 sementes de girassol, foram utilizados 2,5 vezes seu peso seco da solução em questão. Antes da montagem do experimento, o girassol foi armazenado por dez dias, em congelador, de acordo com o recomendado pelas Regras para análises de sementes, para quebrar a dormência desta espécie (BRASIL, 2009).

Procedimentos de assepsia e desinfecção, utilizando-se de bactericida e fungicida, ambos, a $10 \%$ de concentração, foram aplicados às mãos e materiais utilizados na pesquisa. O extrato matriz $(100 \%)$ consistiu em $200 \mathrm{~g}$ de folhas frescas da cártamo trituradas em $1 \mathrm{~L}$ de água destilada, e a partir deste, foram feitas as diluições resultando em extratos com as seguintes concentrações 20, 40, 60 e 80\%, sendo a água destilada utilizada como testemunha, resultando em seis tratamentos.

Os tratamentos, contendo quatro repetições cada, foram mantidos em câmara de germinação, do tipo BOD, 
com fotoperíodo de $12 \mathrm{~h}$ de luz e temperatura de $20^{\circ} \mathrm{C}$ controlados. As sementes de girassol permaneceram na câmara de germinação por dez dias e a canola por sete dias, conforme as Regras para análise de sementes (BRASIL, 2009). Foram feitas avaliações diárias, iniciando-se no dia seguinte a semeadura, sendo considerada como semente germinada aquela que apresentasse no mínimo $2 \mathrm{~mm}$ de radícula (HADAS, 1986). Verificou-se o comprimento de raiz de cinco plântulas por repetição no último dia de avaliação.

O delineamento experimental adotado foi inteiramente casualizado, e ao final dos experimentos, analisaram-se os parâmetros de porcentagem de germinação (PG), calculada segundo a equação citada em Santana e Ranal (2000), tempo médio de germinação (TMG), velocidade média de germinação (VMG), calculada segundo Laboriau (1983) e comprimento médio de raiz primária (CMR).

Os dados para porcentagem de germinação foram transformados em arco seno da raiz quadrada da porcentagem. As análises quanto ao tempo médio de germinação foram efetuadas de acordo com os cálculos de Edmond e Drapalla (1958), segundo a fórmula:

$\mathrm{TMG}=\frac{\left(\mathrm{E}_{1} \cdot \mathrm{T}_{1}\right)+\left(\mathrm{E}_{2} \cdot \mathrm{T}_{2}\right)+\left(\mathrm{E}_{3} \cdot \mathrm{T}_{3}\right)+\ldots+\left(\mathrm{E} \cdot \mathrm{T}_{\mathrm{n}}\right)}{\mathrm{G} 1+\mathrm{G} 2+\mathrm{G} 3+\ldots+\mathrm{Gn}}$

Em que:

TMG = tempo médio de germinação

$\mathrm{E}_{1}, \mathrm{E}_{2}, \mathrm{E}_{3}, \ldots, \mathrm{E}_{\mathrm{n}}=$ número de plântulas computadas na primeira, segunda, terceira e última contagem

$\mathrm{T}_{1}, \mathrm{~T}_{2}, \mathrm{~T}_{3}, \ldots, \mathrm{T}_{\mathrm{n}}=$ número de dias da semeadura à primeira, segunda, terceira e última contagem

onde:

TMG $=$ tempo necessário para atingir a germinação máxima

G1 até $\mathrm{Gi}=$ percentagem de germinação ocorrida a cada dia

$\mathrm{T} 1$ até $\mathrm{Ti}=$ tempo (dias)
Todos os parâmetros foram submetidos à análise de variância (Teste F), sendo as médias comparadas pelo teste de Tukey a 5\% de probabilidade.

\section{Resultados e Discussão}

De acordo com a Tabela 1, o extrato aquoso de folhas de cártamo sobre canola influenciou significativamente os parâmetros, tempo médio de germinação (TMG), velocidade média de germinação (VMG) e comprimento médio de raiz (CMR). Foi constatada interferência inibitória destes parâmetros quando comparado o crescimento inicial das plântulas na testemunha e em extrato das folhas de cártamo, que podem estar relacionadas à potencialidade alelopática da família Asteraceae, como mencionados nos trabalhos de Borgo et al. (2010) e Gaparetto et al. (2010). Nos experimentos não foram realizados testes para verificar o potencial osmótico, o pH e a condutividade elétrica do extrato bruto, que também são fatores que podem influenciar a germinação e desenvolvimento das espécies.

TABELA 1: Porcentagem de germinação (PG), tempo médio de germinação (TMG), velocidade média de germinação (VMG) e comprimento médio de raiz (CMR) de sementes de canola submetidas a extrato aquoso de folhas frescas de cártamo. Cascavel - PR, 2011.

\begin{tabular}{lcccc}
\hline Tratamentos & $\begin{array}{c}\mathbf{1} \text { PG } \\
\text { (\%) }\end{array}$ & $\begin{array}{c}\mathbf{1} \text { TMG } \\
\text { (dias) }\end{array}$ & $\begin{array}{c}\text { 1 VMG } \\
\text { (sementes/ } \\
\text { dias) }\end{array}$ & $\begin{array}{c}\mathbf{1} \text { CMR } \\
\text { (cm) }\end{array}$ \\
\hline Testemunha & $96 \mathrm{a}$ & $1,59 \mathrm{~b}$ & $0,64 \mathrm{a}$ & $5,03 \mathrm{a}$ \\
Extrato a 20\% & $94 \mathrm{a}$ & $1,89 \mathrm{ab}$ & $0,53 \mathrm{ab}$ & $4,17 \mathrm{a}$ \\
Extrato a 40\% & $92 \mathrm{a}$ & $1,98 \mathrm{ab}$ & $0,51 \mathrm{~b}$ & $4,98 \mathrm{a}$ \\
Extrato a 60\% & $94 \mathrm{a}$ & $1,98 \mathrm{ab}$ & $0,51 \mathrm{~b}$ & $2,57 \mathrm{~b}$ \\
Extrato a 80\% & $90 \mathrm{a}$ & $1,95 \mathrm{ab}$ & $0,52 \mathrm{ab}$ & $2,35 \mathrm{bc}$ \\
Extrato a 100\% & $96 \mathrm{a}$ & $2,26 \mathrm{a}$ & $0,44 \mathrm{~b}$ & $1,39 \mathrm{c}$ \\
\hline $\mathrm{CV}(\%)$ & 7,73 & 9,99 & 10,68 & 13,71 \\
\hline
\end{tabular}

${ }^{1}$ Médias seguidas de mesma letra, não diferem significativamente entre si pelo teste de Tukey, ao nível de $5 \%$ de probabilidade. CV(\%) coeficiente de variação.

Observou-se, ainda, que os tratamentos contendo extratos apresentaram maior tempo de germinação das sementes de canola e menor velocidade de germinação dessa cultura, e, além disso, inibiram o crescimento da raiz em maiores concentrações do extrato. Segundo 
Ferreira e Áquila (2000), os efeitos significativos de extratos em relação ao controle, são observados com maior frequência sobre o tempo médio e entropia de germinação, quando comparados com os efeitos na germinabilidade. Esta informação pode ser confirmada nos bioensaios realizados.

Analisando os dados referentes ao tempo médio de germinação (TMG), verificou-se que apenas o tratamento testemunha e o tratamento com extrato a $100 \%$ diferiram significativamente. O extrato matriz a $100 \%$ aumentou o tempo de germinação em $42 \%$, o que significa o atraso de um dia para as sementes germinarem quando comparadas à testemunha. Como consequência, a velocidade média de germinação também foi influenciada, apresentando diferenças significativas entre a testemunha e os tratamentos com extrato das folhas de cártamo a 40, 60 e $100 \%$. Quando comparado com a testemunha, o tratamento contendo extrato matriz a $100 \%$ reduziu a velocidade de germinação em aproximadamente $31 \%$.

A velocidade de germinação é um indicativo de capacidade de emergência das plântulas, o que a torna uma variável importante. $\mathrm{O}$ atraso da germinação faz com que as plântulas demorem mais para emergir, tornando-se propensas ao ataque de predadores, pragas e patógenos e ainda, este atraso pode resultar em uma competição intra e interespecífica por recursos do meio devido aos diferentes tamanhos das plantas existentes no mesmo ambiente (KAPPES et al., 2010).

Corsato et al. (2010), ao testarem extrato aquoso de girassol (Asteraceae) sobre soja transgênica (cultivar CD213RR) (Glycine max L. Merril), observaram que o extrato das folhas influenciaram negativamente o tempo médio de germinação, atrasando a germinação das sementes de soja. Estes resultados, semelhantes aos deste trabalho, demonstram a presença de substâncias inibitórias nas espécies dessa família.

No entanto, estes resultados são contrários aos obtidos por Farhoudi e Lee (2012) em estudos de extrato de cártamo sobre nabo-selvagem (Sinapis arvensis L.), onde foi observada uma diminuição no tempo de germinação das sementes de nabo quando submetidas aos tratamentos contendo extrato, aumentando, portanto, a velocidade de germinação das sementes.
Em relação ao comprimento médio de raiz, também foi constatado influência dos compostos aleloquímicos presentes nas folhas de cártamo. A partir do tratamento com extrato a $60 \%$ observou-se uma redução significativa do comprimento médio da raiz. Quando comparado à testemunha, o tratamento com extrato a $60 \%$ proporcionou uma redução do comprimento médio de raiz de aproximadamente $2,46 \mathrm{~cm}$. Já quando comparamos a testemunha com o tratamento com extrato a $100 \%$ observou-se uma redução de aproximadamente $4 \mathrm{~cm}$.

Os dados encontrados também corroboram com Spiassi et al. (2011). Em experimentos de diferentes palhadas sobre o crescimento inicial do milho, os autores observaram que a palhada de cártamo apresentou efeito inibitório sobre o crescimento radicular das plântulas de milho.

Resultados semelhantes foram encontrados por Farhoudi e Lee (2012), em estudos de extratos de cártamo sobre nabo-selvagem, pertencente à mesma família da canola. Os autores observaram efeito inibitório dessa espécie sobre o nabo, onde também constataram que o aumento da concentração do extrato de cártamo diminui a germinação e o crescimento das raízes de plântulas de nabo, assim como os dados obtidos nesse trabalho.

Uma hipótese que pode ser responsável por este efeito inibitório do extrato de folhas de cártamo sobre as raízes de canola, provavelmente, seja a presença de lactonas sesquiterpênicas, que, segundo Kim et al. (2006), é um dos principais metabólitos secundários da família Asteraceae, encontrado em diversas plantas dentre elas o girassol (Helianthus annuus L.) e o crisântemo (Chrysanthemum cinerariaefolium L.). Este composto pode ser depositado diretamente no solo pela água da chuva ou gradualmente liberado durante a decomposição das folhas, afetando o crescimento de plantas vizinhas (FRITZ et al., 2007).

Além das lactonas sesquiterpênicas, outros compostos, que quando liberados no solo podem limitar o crescimento de algumas plantas, são os compostos fenólicos (TAIZ; ZEIGER, 2009). Sabe-se que muitas espécies da família Asteraceae possuem estes compostos, 
dentre elas o cártamo, no qual foi identificada a presença de compostos fenólicos e c-cumárico nas suas sementes em trabalhos realizados por Sakamura et al. (1980) e Abud et al. (2010).

Portanto, se a redução do crescimento da raiz de canola e o atraso do seu desenvolvimento forem confirmados a campo, estes resultados podem ser prejudiciais à planta e a sua produtividade, pois a raiz é um órgão fundamental, responsável pela absorção de água e nutrientes minerais. Quando esta parte da planta é afetada, consequentemente o crescimento e desenvolvimento também serão afetados. Contudo, são necessários estudos mais aprofundados sob a ação dos compostos aleloquímicos, porque estas substâncias podem ser afetadas por diversos fatores quando em condições ambientais, como por exemplo, o estresse e a ação de microorganismos.

Com relação à cultura do girassol, pode-se observar, na Tabela 2, que as sementes desta espécie quando submetidas ao extrato aquoso de folhas de cártamo em diferentes concentrações, não apresentaram diferenças significativas em relação à testemunha, não apresentando, portanto, interferência alelopática.

$\mathrm{Na}$ maioria dos estudos, sempre é relatado à interferência alelopática, seja ela positiva ou inibitória, como verificado em estudos realizados por Áquila et al. (1999) em testes de potencial alelopático de macela (Achryrocline satureoides (Lam.) DC.) (Asteraceae) sobre alface (Asteraceae). Os autores relataram o efeito benéfico de algumas espécies sobre outras, confirmados em seus experimentos, onde, verificaram que extrato de folhas estimulou o crescimento de raízes da alface (Asteraceae).

Contrário de Áquila et al. (1999), estudos realizados por Carreira et al. (2005) relatam o efeito alelopático inibitório de carqueja (Baccharis trimera (Less.) DC.), pertencente à mesma família do cártamo, DC. em seus experimentos com extratos aquosos e etanólicos, sobre alface. Os resultados encontrados demonstraram que a espécie possui substâncias que apresentam elevada inibição da germinação das sementes de alface.
TABELA 2: Porcentagem de germinação (PG), tempo médio de germinação (TMG), velocidade média de germinação (VMG) e comprimento médio de raiz (CMR) de sementes de girassol submetidas a extrato aquoso de folhas frescas de cártamo. Cascavel - PR, 2011.

\begin{tabular}{lllll}
\hline Tratamentos & $\begin{array}{c}\mathbf{1} \text { PG } \\
(\mathbf{\%})\end{array}$ & $\begin{array}{c}\mathbf{1}^{\mathbf{1}} \mathbf{T M G} \\
\text { (Dias) }\end{array}$ & $\begin{array}{c}\mathbf{1} \text { VMG } \\
\text { (Sementes/ } \\
\text { Dias) }\end{array}$ & $\begin{array}{c}\mathbf{1} \text { CMR } \\
(\mathbf{c m})\end{array}$ \\
\hline Testemunha & $56,0 \mathrm{ab}$ & $2,26 \mathrm{ab}$ & $0,45 \mathrm{ab}$ & $3,06 \mathrm{a}$ \\
Extrato a 20\% & $51,5 \mathrm{~b}$ & $2,79 \mathrm{a}$ & $0,37 \mathrm{ab}$ & $4,93 \mathrm{a}$ \\
Extrato a 40\% & $51,5 \mathrm{~b}$ & $2,04 \mathrm{~b}$ & $0,49 \mathrm{ab}$ & $4,64 \mathrm{a}$ \\
Extrato a 60\% & $67,0 \mathrm{a}$ & $2,42 \mathrm{ab}$ & $0,42 \mathrm{ab}$ & $6,37 \mathrm{a}$ \\
Extrato a 80\% & $56,5 \mathrm{ab}$ & $1,91 \mathrm{~b}$ & $0,54 \mathrm{a}$ & $5,98 \mathrm{a}$ \\
Extrato a 100\% & $69,0 \mathrm{a}$ & $2,38 \mathrm{ab}$ & $0,42 \mathrm{~b}$ & $6,00 \mathrm{a}$ \\
\hline CV (\%) & 10,44 & 13,71 & 22,36 & 37,71 \\
\hline
\end{tabular}

${ }^{1}$ Médias seguidas de mesma letra, não diferem significativamente entre si pelo teste de Tukey, ao nível de $5 \%$ de probabilidade. $\mathrm{CV}(\%)$ coeficiente de variação.

Concordando com os resultados obtidos por Carreira et al. (2005), Baratto et al. (2008) e Bach e Silva (2010) também observaram efeito inibitório entre espécies da família Asteraceae. Baratto et al. (2008) observaram um notável efeito alelopático de extrato de guaco (Asteraceae) em sementes de alface. Segundo os autores, o extrato do guaco tradicional inibiu completamente a germinação das sementes em todas as concentrações testadas, enquanto que o extrato do guaco hidropônico teve $53 \%$ das sementes inibidas na concentração de $5 \mathrm{mg} / \mathrm{mL}$ e $100 \%$ de inibição da germinação nas demais concentrações. Também verificaram uma maior atividade alelopática do extrato etanólico do guaco tradicional, em comparação ao hidropônico, uma vez que o primeiro inibiu completamente a germinação das sementes mesmo na menor concentração do extrato. Bach e Silva (2010) observaram que o extrato aquoso de picão-preto (Asteraceae) inibiu a germinação de sementes de alface a partir de extrato a $20 \%$ e, consequentemente, interferiram no tempo médio, velocidade média e comprimento médio de raiz.

Assim, comparando os estudos citados anteriormente e os resultados obtidos neste trabalho, quanto ao efeito dos compostos alelopáticos de cártamo sobre girassol e canola, podemos reforçar que: mesmo que as espécies pertençam à mesma família os compostos existentes podem ser diferentes, e ainda, uma mesma 
espécie possui vários compostos aleloquímicos que atuam diferentemente sobre a espécie-alvo, sendo que a resposta das plantas aos compostos aleloquímicos pode variar conforme a espécie testada e sua sensibilidade a determinado composto, Como foi observada neste experimento, em que um mesmo extrato atuou de forma distinta sobre a canola e o girassol.

Esta variação de efeitos alelopáticos entre as espécies também foi observada em estudos de extratos de folha e caule de girassol (Asteraceae) sobre pepino, tomate e alface, realizados por Ciarka et al. (2004). Nos experimentos os autores constataram que o pepino foi o menos afetado pelos extratos aquosos de girassol. Esta variação de resposta pode ser atribuída à sensibilidade diferencial das espécies, como também à técnica utilizada para avaliar a alelopatia. Assim, diferentes espécies podem apresentar maior ou menor sensibilidade aos aleloquímicos.

Quanto ao efeito alelopático das substâncias liberadas pelas folhas de cártamo ainda há escassez de literatura que relate o estímulo ou inibição de espécies vegetais. Sabe-se que as plantas apresentam compostos secundários, entre eles os compostos fenólicos, e também, que muitas espécies da mesma família apresentam compostos aleloquímicos que podem interferir em outras plantas. Assim há necessidade de maiores estudos para identificação dos possíveis compostos alelopáticos, e como eles agem sobre outras espécies.

Em virtude desses resultados e da comparação deles com os trabalhos acima citados, entende-se que o cártamo não interfere negativamente na germinação e no desenvolvimento do girassol, sendo assim, pode ser considerada como alternativa para uso no sistema de plantio direto. Porém, o extrato de cártamo influenciou de maneira inibitória a germinação e o crescimento inicial da canola, sendo necessário, portanto, maiores estudos em relação a esses efeitos.

Nas condições em que foi desenvolvido o presente trabalho, conclui-se, que o extrato das folhas de cártamo apresentou efeito alelopático inibitório sobre canola e não apresentou interferência alelopática sobre o girassol.

\section{Referências}

ABUD, H. F.; GONÇALVES, N. R.; REIS, R. G. E.; GALLÃO, M. I.; INNECCO, R. Morfologia de sementes e plântulas de cártamos. Revista Ciência Agronômica, Fortaleza, v. 41, n. 2, p. 259-265, 2010. ÁQUIlA, M. E. A.; UNGARETTI, J. A. C.; MICHELIN, A. Preliminary observation on allelopathic activity in Achryrocline satureioides (Lam) DC. Acta Horticulturae, Leuven, v. 502, p. 383 387, 1999.

BACH, F. T.; SILVA, C. A. T. Efeito alelopático de extrato aquoso de boldo e picão preto sobre a germinação e desenvolvimento de plântulas de alface. Cultivando o saber, Cascavel, v. 3, n. 2, p. 190-198, 2010.

BARATTO, L.; LANG, K. L.; VANZ, D. C.; REGINATT, F. H.; OLIVEIRA, J. B.; FALKENBERG, M. Investigação das atividades alelopática e antimicrobiana de Mikania laevigata (Asteraceae) obtida de cultivos hidropônico e tradicional. Revista Brasileira de Farmacognosia, Curitiba, v. 18, n. 4, p. 577-582, 2008.

BORELLA, J.; PASTORINI, L. H. Influência alelopática de Phytolacca dioica L. na germinação e crescimento inicial de tomate e picão-preto. Biotemas, Florianópolis, v. 22, n. 3, p. 67-75, 2009.

BORGO, J.; XAVIER, C. A. G.; MOURA, D. J.; RICHTER, M. F.; SUYENAGA, E. S. Influência dos processos de secagem sobre o teor de flavonoides e na atividade antioxidante dos extratos de Baccharis articulata (Lam.) Pers., Asteraceae. Revista Brasileira de Farmacognosia, Curitiba, v. 20, n. 1, p 12-17, 2010.

BORTOLINI, M. F.; FORTES, A. M. T. Efeitos alelopáticos sobre a germinação de sementes de soja (Glycine max L. Merrill). Semina: Ciências Agrárias, Londrina, v. 26, n. 1, p. 5-10, 2005.

BRASIL. Empresa Brasileira de Pesquisas Agronômicas. Inseticidas botânicos: seus princípios ativos, modo de ação e uso agrícola. Seropédica: Embrapa Agrobiologia, 2005. 58 p.

BRASIL. Ministério da Agricultura, Pecuária e Abastecimento. Regras para análise de sementes. Mapa/ACS. Brasília: Secretaria de Defesa Agropecuária, 2009. 399 p.

CARVALHO, A. M. Como rotacionar cultivos. DBO Agrotecnologia, São Paulo, v. 1, n. 1, p. 30-31, 2006.

CARVALHO, W. P.; CARVALHO, G. J.; ANDRADE, M. J. B.; FONSCECA, G.; ANDRADE, L.; VALACI, F.; OLIVEIRA, D. P. Alelopatia de adubos verdes sobre feijoeiro comum (Phaseolus vulgaris L.). Revista Brasileira de Biociências, Porto Alegre, v. 10, n. 1, p. 86-93, 2012.

CARREIRA, R. C.; TORRES, L. M. B.; YOUNG, M. C. M.; ZAIDAN, L. B. Efeitos alelopáticos de extratos de Baccharis trimera na germinação de sementes de alface. In: REUNIÓN DE LA SOCIEDAD LATINOAMERICANA DE FITOQUÍMICA, V, 2005, Montevideo. Resumos... Montevideo: SLAF, 2005. Versão eletrônica. CIARKA, D.; GAWRONSKA, H.; GAWRONSKI, S. W. Crops species reaction to sunflower allelopathics. In: EUROPEAN ALLELOPATHY SYMPOSIUM "ALLELOPATHY - FROM UNDERSTANDING TO APPLICATION”, 2004, Pulawy. Proceedings... Pulawy, 2004. Versão eletrônica.

CORSATO, J. M; FORTES, A. M. T.; SANTORUM, M.; LESZCZYNSKI, R. Efeito alelopático do extrato aquoso de folhas de girassol sobre a germinação de soja e picão-preto. Semina: Ciências Agrárias, Londrina, v. 31, n. 2, p. 353-360, 2010.

EDMOND, J. B.; DRAPALLA, W. J. The effects of temperature, sana and soil, and acetone on germination oj okra seed. Proceedings of the 
American society for Horticuticulral Science, Alexandria, v. 71, p. 428-443, 1958.

EL-LATTIEF, E. A. Evaluation of 25 safflower genotypes for seed and oil yields under arid environment in upper Egypt. Asian Journal of Crop Science, Pakistan, v. 4, n. 2, p. 72-79, 2012.

FARHOUDI, R.; LEE, D. J. Evaluation of safflower (Carthamus tinctorius $\mathrm{cv}$. Koseh) extract on germination and induction of $\alpha$-amylase activity of wild mustard (Sinapis arvensis) seeds. Seed Science and Technology, Zurich, v. 40, n. 1, p. 134-138, 2012.

FERREIRA, A. G.; ÁQUILA, M. E. A. Alelopatia: uma área emergente da ecofisiologia. Revista Brasileira de Fisiologia Vegetal, Campinas, v. 12, p. 175-204, 2000.

FRITZ, D.; BERNARDI, A. P.; HAAS, J. S.; ASCOLI, B. M.; BORDIGNON, S. A. L.; VON POSER, G. Germination and growth inhibitory effects of Hypericum myrianthum and $H$. polyanthemum extracts on Lactuca sativa L. Revista Brasileira Farmacognosia, Curitiba, v. 17, n. 1, p. 44-48, 2007.

GASPARETTO, J. C.; CAMPOS, F. R.; BUDEL, J. M.; PONTAROLO, R. Mikania glomerata Spreng. e M. laevigata Sch. Bip. ex Baker, Asteraceae: estudos agronômicos, genéticos, morfoanatômicos, químicos, farmacológicos, toxicológicos e uso nos programas de fitoterapia do Brasil. Revista Brasileira de Farmacognosia, Curitiba, v. 20, n. 4, p. 627-640, 2010.

HADAS, A. Water uptake germination of leguminous seeds under changing external water potential in osmotic solution. Journal Experimental of Botany, Oxford, v. 27, n. 98, p. 480-489, 1976.

IAS - INTERNATIONAL ALLELOPATHY SOCIETY. Constitution and Bylaws. 2012. Disponível em $<$ http://www-ias.uca.es/bylaws. htm\#SECTION>. Acesso em: 05 abril 2012.

INTA - INSTITUTO NACIONAL DE TECNOLOGIA AGROPECUÁRIA. Cultivo de Cártamo - Ensayos em la zona. Buenos Aires: Instituto Nacional de Tecnología Agropecuaria, 2008. s/ paginação. (Hoja Técnica n. 4.)

KAPPES, C.; COSTA ANDRADE, J. A. da C.; HAGA, K. I.; FERREIRA, J. P.; ARF, M. V. Geminação, Vigor de sementes e crescimento de plântulas de milho sob condições de déficit hídrico. Scientia Agraria, Curitiba, v. 11, n. 2, p. 125-134, 2010.

KIM, S. H.; SONG, J. S.; CHOI, B. G.; KIM, H.; KIM, T. S. Chemical modification of santonin into a diacetoxy acetal form confers the ability to induce differentiation of human promyelocytic leukemia cells via the doen-regulation of NF-kB DNA bindingactivity. The Journal of Biological Chemistry, New York, v. 281, n. 19, p. 13117-13125, 2006. KUPIDLOWSKA, E.; GNIAZDOWSKA, A.; STEPIEN, J.; CORBINEAU, F.; VINEL, D.; SKOCZOWSKI, A.; JANECZKO, A.; BOGATEK, R. Impact of sunflower (Helianthus annuus L.) extracts upon reserve mobilization and energy metabolism in germinating mustard (Sinapis alba L.) seeds. Journal Chemical of Ecology, New York, v. 32, n. 12, p. 2569-2583, 2006.

LABORIAU, L. G. A. A germinação de sementes. Washington: Organização dos estados Americanos, 1983. 174 p.

LARCHER, W. Ecofisiologia vegetal. São Carlos: Rima, 2000. 531 p. LORENZI, H.; MATOS, F. J. A. Plantas medicinais no Brasil: nativas e exóticas. 2 ed. Nova Odessa: Plantarum, 2008. 544 p.

LOUSADA, L. L.; LEMOS, G. C. S.; FREITAS, S. P.; DAHER, R. F.; ESTEVES, B. S. Bioatividade de extratos hidroalcoólicos de Cymbopogon citratus (DC.) Stapf. sobre picão-preto (Bidens pilosa L.) e alface (Lactuca sativa L.). Revista Brasileira de Plantas Medicinais, Botucatu, v. 14, n. 2, p. 282-286, 2012.
MACÍAS, F. A.; MOLINILLO, J. M. G.; VARELA, R. M.; GALINDO, J. C. G. Allelopathy - natural alternative for weed Control. Pest Management Science, Malden, v. 63, p. 327-348, 2007.

OLIVEIRA, A. K.; COELHO, M. F. B.; MAIA, S. S. S.; DIÓGENES, F. E. P. Atividade alelopática de extratos de diferentes orgãos de Caesalpinia ferrea na germinação de alface. Ciência Rural, Santa Maria, v. 42, n. 8, p. 1397-1403, 2012.

OLIVEIRA, A. S.; PEREIRA, R. A.; LIMA, L. M.; MORAIS, A. H. A.; MELO, F. R.; FRANCO, O. L.; BLOCH Jr., C.;GROSSI-DE-SÁ, M. F.; SALES, M. P. Activity toward bruchid pest of a Kunitz-type inhibitor from seeds of the algaroba tree (Prosopis juliflora DC). Pesticide Biochemistry and Physiology, Amherst, v. 72, p. 122- 132, 2002.

OLIVEIRA, G. G. 2007. Trichoderma spp. no crescimentovegetal e no biocontrole de Sclerotinia sclerotiorum e de patógenos em sementes de (Carthamus tinctorius). 2007. 77 f. Dissertação (Mestrado em Agronomia) - Universidade Federal de Santa Maria, Santa Maria. 2007.

PINTÃO, A. M.; SILVA, I. F. A Verdade sobre o açafrão. In: WORKSHOP PLANTAS MEDICINAIS E FITOTERAPÊUTICAS NOS TRÓPICOS, 9, 2008, Lisboa. Resumos... Lisboa: IICT /CCCM, 2008. Versão Eletrônica.

RADOSEVICH, S. R.; HOLT, J. S.; GHERSA, C. Weed ecology: implications for management. New York: Wiley, 1997. 589 p.

RURAL. Cártamo alternativa verão/inverno. 2013. Disponível em $\quad<$ http://www.ruralbioenergia.com.br/default. asp?tipo $=1 \&$ secao $=$ cartamo_veraoinverno.asp $>$. Acesso em: 19 fevereiro 2013.

SAKAMURA, S.; TERAYAMA, Y.; KAWAKATSU, S.; ICHIHARA, A.; SAITO, H. Conjugated serotonins related to cathartic activity in safflower seeds (Carthamus tinctorius L.). Agricultural and Biological Chemistry, Tokio, v. 44, n. 12, p. 2951-2954, 1980.

SANTANA. D. G.; RANAL. M. Análise Estatística na Germinação. Revista Brasileira de Fisiologia Vegetal, Campinas, v. 12 (Edição Especial), p. 205-237, 2000.

SILVA, J.; FORTES, A. M.T.; GOMES, F. M.; PINTO, T. T.; BONAMIGO, T.; BOIAGO, N. P. Alelopatia de Camelina sativa Boiss. (Brassicaceae) sobre a germinação e desenvolvimento inicial de Bidens pilosa (L.) e Glycine max (L.) Merr. Biotemas, Florianópolis, v. 24, n. 4, p. 17-24, 2011.

SPIASSI, A.; FORTES, A. M. T.; PEREIRA, D.C.; SENEM, J.; TOMAZONI, D. Alelopatia de palhadas de coberturas de inverno sobre o crescimento inicial de milho Semina: Ciências Agrárias, Londrina, v. 32, n. 2, p. 577-582, 2011.

TAIZ, L.; ZEIGER, E. Fisiologia vegetal. Porto Alegre: Artmed, 2009. $818 \mathrm{p}$.

ULLAH, F.; BANO. A. Effect of plant growth regulators on oil yield and biodiesel production of safflower (Carthamus tictorius L.). Brazilian Society of Plant Physiology, Rio Claro, v. 21, n. 1, p. $27-$ 31, 2011.

VERDI, L. G.; BRIGHENTE, I. M. C.; PIZZOLATI, M. G. Gênero Baccharis: Aspectos Químicos, Econômicos e Biológicos. Química Nova, São Paulo, v. 28, n. 1, p. 85-94, 2005.

VIVAS, M. J. Culturas alternativas - Cártamo, Sésamo e Camelina. Melhoramento, Portugal, v. 38, p. 183-192, 2002. 